\title{
Synthesized Zeolite from Coal Fly Ash: Effect of Furnace and Acidic Pretreatment on the Characteristic
}

\author{
Aini Nadhokhotani Herpi ${ }^{1}$, Rika Tri Yunarti ${ }^{2}$, Asep Saefumillah ${ }^{3}$ \\ \{aininadhokhotani@ui.ac.id ${ }^{1}$, rika.tri@sci.ui.ac.id ${ }^{2}$, asep.saefumillah@sci.ui.ac.id ${ }^{3}$ \} \\ Department of Chemistry, Faculty of Mathematics and Natural Sciences (FMIPA), \\ Universitas Indonesia. Kampus UI Depok, Depok 16424, Indonesia
}

\begin{abstract}
Waste management is a widespread problem all across the world. Fly ash is one of the wastes generated in a large amount, where disposal of fly ash by landfill takes up agricultural lands and also causes serious problems in the respiratory system. Meanwhile, fly ash contains high silica-alumina, so that it can be used as a raw material to synthesize zeolite. In this work, fly ash from industrial synthesized into zeolite type $\mathrm{NaP} 1$, and the effectiveness of furnace and acidic pretreatment was studied. The synthesis of class F fly ash from Indonesia was subjected to a 36-hour hydrothermal reaction with sodium hydroxide. Synthesized zeolite was characterized by X-ray diffractometry to obtain the crystal structure of the zeolite, X-ray fluorescence to obtain the mineral composition, and SEM to obtain morphological study XRF data shows that pretreatment of fly ash has no significant effect on the content of fly ash itself, however, when fly ash was converted into zeolites, the resulting zeolites had a higher crystallinity compared to fly ash without pretreatment. It was found that the most effective pretreatment was when zeolite formed from fly ash with acidic pretreatment using $20 \mathrm{wt} \% \mathrm{HCl}$ at $80 \mathrm{oC}$ for 2 hours.
\end{abstract}

Keywords: coal, coal fly ash, fly ash pretreatment, zeolite, hydrothermal

\section{Introduction}

Fly ash is a waste of coal combustion which formed from a mineral substance based on silica-alumina [1]. Coal production worldwide is estimated at 780 million tonnes per year [2][3]. Moreover, Indonesia has a large amount of power plant producing fly ash as its by-product. Fly ash contains amorphous alumina-silicate material, mainly quartz $\left(\mathrm{SiO}_{2}\right)$, mullite $\left(3 \mathrm{Al}_{2} \mathrm{O}_{3} \cdot 2 \mathrm{SiO}_{2}\right)$, hematite $\left(\mathrm{Fe}_{2} \mathrm{O}_{3}\right)$, magnetite $\left(\mathrm{Fe}_{3} \mathrm{O}_{4}\right)$, and more elements and their oxides in a trace amount to several percentages [4][5]. Among all fly ash produced, the utilization of fly ash is only about $25 \%$, and the rest is disposed of as waste that causes environmental issues [6]. If untreated, fly ash waste must be isolated to avoid the movement of pollutants such as heavy metals into agricultural or aquatic environments [7]. Therefore, the utilization of fly ash gets more attention and becomes the most common waste studied [8].

Many studies have been conducted using fly ash as raw material, including using fly ash as a raw material for zeolite synthesis [9][10], construction / industrial work [11], removal of toxic metals [12], removing inorganic compounds [13], removing dyes [14], etc. In this work, fly ash was synthesized into zeolite, and the effect of pretreatment on the resulting zeolite was studied. Zeolitization of fly ash could be an ideal yet inexpensive method to utilize fly ash and reduce its impact on the environment [3]. Zeolites are microporous, hydrated aluminosilicates 
structured into three-dimensional networks of tetrahedra $\mathrm{TO}_{4}(\mathrm{~T}=\mathrm{Si}, \mathrm{Al})$ joined at the corners by oxygen atoms [4], which, in its crystal structure, contain numerous channels and chambers of different size that provides various sorption ion exchange and catalyst properties [6]. Previous researchers have conducted several studied to synthesize zeolite from fly ash by hydrothermal conversion with alkali solution study various parameters that alter configuration and properties of zeolite [3][6][15]. This paper focuses on how pretreatment affects the properties of zeolite. Zeolite synthesized from fly ash allows waste converted into high-value products of cations, which have wide applications used as adsorbents, molecular sieves, wastewater treatment, and many more [15][6]. There are additional measures here in this work that boost the characteristics and quality of the zeolite compared to zeolite without any pretreatment. A previous study shows that thermal stability and the behavior of the resulting zeolite are improved by acidic pretreatment [5] while another study shows that furnace pretreatment increases the adsorption capacity of synthesized zeolite [3]. This study compared the effect of those two pretreatments by analyzing the characteristic of raw fly ash, zeolite synthesized with fusion pretreatment, and zeolite synthesized with acidic pretreatment.

\section{Method}

\subsection{Fly ash and reagents}

The raw fly ash used in the experiment was obtained from PT Sinar Mas Argo Resources and Technology (SMART Tbk), Indonesia. SMART Tbk is a leading agribusiness company that focused on sustainable palm oil production. According to the American Society for Testing and Materials (ASTM) C618, the fly ash used in this experiment is F type because the sum of the major compound $\left(\mathrm{SiO}_{2}, \mathrm{Al}_{2} \mathrm{O}_{3}\right.$, and $\left.\mathrm{Fe}_{2} \mathrm{O}_{3}\right)$ is over $70 \%$ and $\mathrm{SO}_{3}$ less than $5 \%$. The reagent used in this research is sodium hydroxide (Merck, $\geq 99 \%$ ), hydrochloric acid 37\% with analytical purity.

\subsection{Material characterization}

The chemical compositions of fly ash and zeolite samples were determined using Panalytical Epsilon1 X-ray fluorescence spectroscopy (XRF). The X-ray diffractions (XRD) analysis was conducted using Panalytical X'Pert Pro MPD. The $2 \theta$ range was from $5^{\circ}$ to $40^{\circ}$ with $\mathrm{Cu} \mathrm{K} \alpha$ radiation. The morphology analyses were performed using FEI Quanta 650 Scanning Electron Microscopy (SEM).

\subsection{Preparation of zeolite}

The amorphous $\mathrm{SiO}_{2}$ and $\mathrm{Al}_{2} \mathrm{O}_{3}$ in fly ash are used as silica and aluminum source for the synthesis of zeolite. Fly ash was screened through a sieve shaker of 80 mesh size to remove coarse particles and dried at $150{ }^{\circ} \mathrm{C}$ for 4 hours. For each type of zeolite, the following process pretreatment were applied: 1) calcination process of fly ash at $850^{\circ} \mathrm{C}$ for 2 hours, 2) treatment with hydrochloric acid $(20 \mathrm{wt} \% \mathrm{HCl})$ at $80^{\circ} \mathrm{C}$ for $2 \mathrm{hr}$ (solid/liquid ratio of $\left.1: 10\right)$. Both fly ash with different pretreatment underwent a hydrothermal reaction: 10 gr of fly ash, 6 gr of $\mathrm{NaOH}$, and $45 \mathrm{ml}$ of double-distilled water at $80{ }^{\circ} \mathrm{C}$ for 36 hours. 


\section{Results and Discussion \\ 3.1 Zeolite Synthesis Condition}

Three types of fly ash are used to determine the effect of pretreatment on the resulting zeolite namely fly ash without pretreatment (FA), fly ash with furnace pretreatment (FA-1), and fly ash with acidic pretreatment, so that there are three types of zeolite produced, namely zeolite from fly ash without pretreatment (ZE), zeolite from fly ash with furnace pretreatment (ZE-1) and zeolite from fly ash with acidic pretreatment (ZE-2). Both fly ash samples were screened through an 80 mesh size sieve shaker and heated for 4 hours at $150{ }^{\circ} \mathrm{C}$ to extract the moisture in the sample. All fly ash samples were screened through a sieve shaker of 80 mesh size and heated at $150^{\circ} \mathrm{C}$ for 4 hours to remove moisture contained in the sample. RFA sample obtained by directly synthesizing the fly ash by a hydrothermal method in an autoclave at $80{ }^{\circ} \mathrm{C}$ for 36 hours, resulting ZE sample. FA-1 sample was obtained by providing furnace pretreatment at a temperature of $650^{\circ} \mathrm{C}$ for 2 hours, resulting in a light brown fly ash. The FA-1 sample was then synthesized by the same hydrothermal method resulting in ZE-1 sample. The FA-1 sample was then synthesized by the same hydrothermal method resulting in ZE-1 sample. Meanwhile, FA2 sample was pre-treated by reacting fly ash with $20 \%$ hydrochloric acid with a solid : liquid ratio of $1: 10$ at $80^{\circ} \mathrm{C}$ for 2 hours produces fly ash with a grey color that is lighter than RFA. FA-2 was washed to a neutral $\mathrm{pH}$ and then synthesized by the same hydrothermal method resulting in ZE-2 sample. In order to assess the effect of fly ash quality on the zeolite made, the use of various starting materials was investigated. The hydrothermal process includes the dissolution of fly ash in an alkaline solution and the synthesis by thermal treatment of zeolite materials [17]. Formation of zeolite performed according to the following chemical reaction:

$$
\text { Fly ash }+3.3 \mathrm{~mol} \mathrm{dm}^{-3} \mathrm{NaOH} \quad \stackrel{36 \mathrm{hr}, 80^{\circ} \mathrm{C}}{\longrightarrow} \quad \text { zeolite + residiuum }
$$

\subsection{Characterization of Synthesized Zeolite}

Table 1 shows the chemical composition and molar $\mathrm{Si} / \mathrm{Al}$ ratio of all materials used in this work. The main components of the three types of fly ashes were the oxide form of $\mathrm{Si}, \mathrm{Al}, \mathrm{Fe}$ accounting for around $83 \%$ and there were no significant variations in compositions between them. Meanwhile, there were significant differences between synthesized materials where ZE2 has the highest main component percentage. As a result of this composition, ZE-2 is classified as a material with high silica and alumina content and low-level impurities [18]. The molar $\mathrm{Si} / \mathrm{Al}$ ratio of RFA, FA-1, FA-2, ZE, and ZE-1 was similar around 2.69 to 2.77. As shown in Table 1, acidic pretreatment decreases the unwanted portion by a substantial amount. This influenced the percentage of $\mathrm{Si}$ and $\mathrm{Al}$, which are the key components of the zeolite formation. An increase in $\mathrm{wt} \%$ of $\mathrm{Si}$ and a decrease in wt $\%$ of $\mathrm{Al}$ led to an increase in molar $\mathrm{Si} / \mathrm{Al}$ ratio to 4.83 which could cause the resulting zeolite tends to have a high level of crystallinity.

Based on the key d-spacing dhkl $=6.21,5.59,4.53,3.89,3.76,3.39,3.12,2.97$, and 2.54 $\AA$, the presence of the ZE zeolitic phase in the reaction products was determined. On the basis of the key d-spacing dhkl $=6.17,5.59,4.53,3.90,3.77,3.41,3.11,2.99$ and $2.54 \AA$, the presence of the ZE-1 zeolitic phase in the reaction products was calculated. Based on the key d-spacing $\mathrm{dhkl}=6.17,4.53,3.90,3.76,3.12,2.98$, and $2.544 \AA$ the presence of the ZE-2 zeolitic phase in the reaction products was determined. There were no significant differences between XRD diffractogram of RFA, FA-1, and FA-2, each of them was composed of an amorphous phase with a low quantity of crystalline (quartz and $\mathrm{NaP1}$ ). The highest XRD intensities appear on zeolite with acidic pretreatment suggested that acidic pretreatment is required to generate higher crystallized zeolite. In the XRD patterns, the weak peaks of ZE-1 indicate the conversion from 
the amorphous phase to the zeolite phase occurred. Formation of zeolite from fly ash without any pretreatment results in a zeolite with lower XRD intensities.

Table 1. Chemical composition and molar ratio $\mathrm{Si} / \mathrm{Al}$ of fly ash and synthesized zeolite

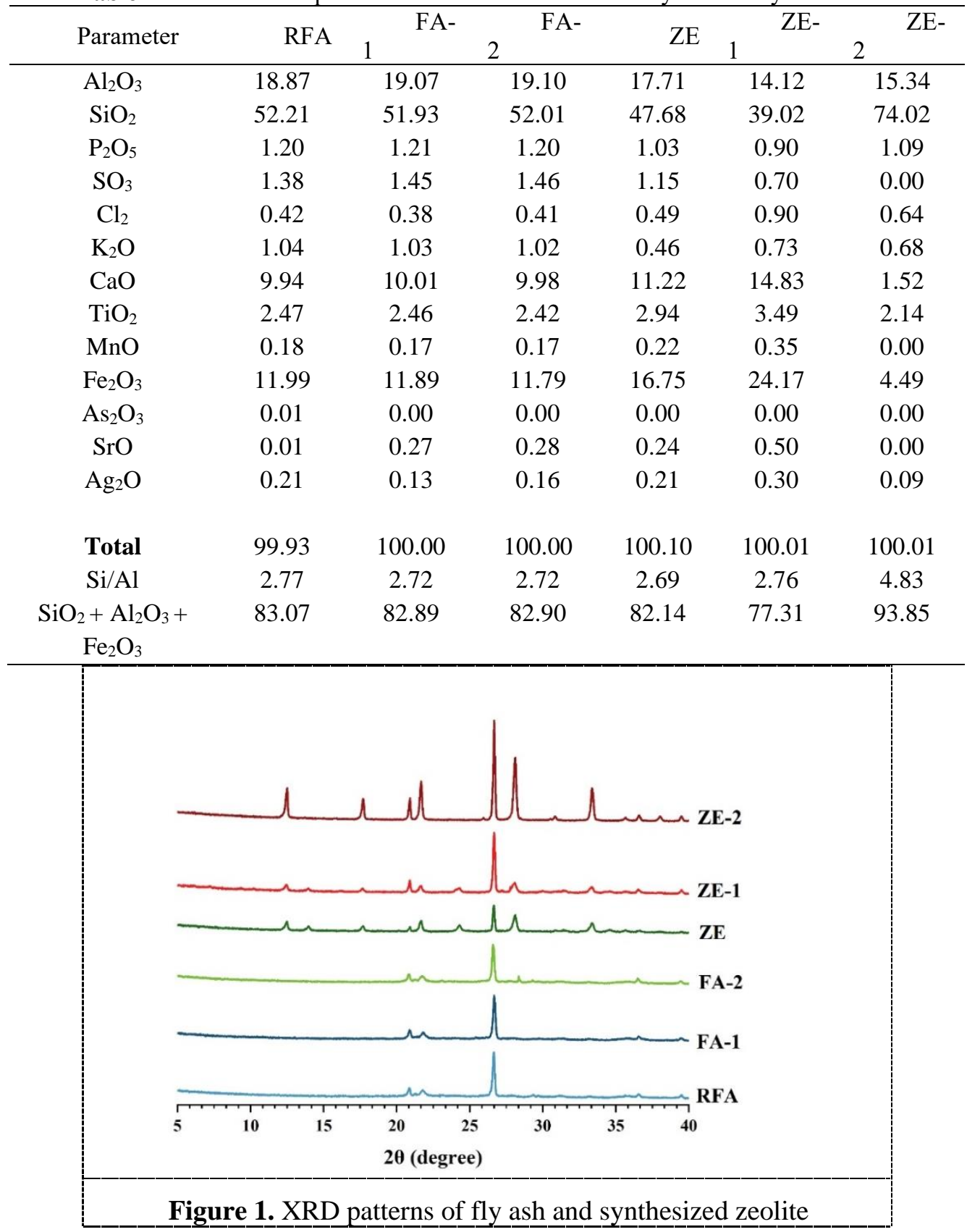


The surface morphology of fly ash in Figure 2 suggested that amorphous aluminosilicate spheres were the dominant morphological types occurring in the studied fly ash, while Figure 3 displayed structures of zeolite $\mathrm{NaP} 1$ type as previously reported in the literature.
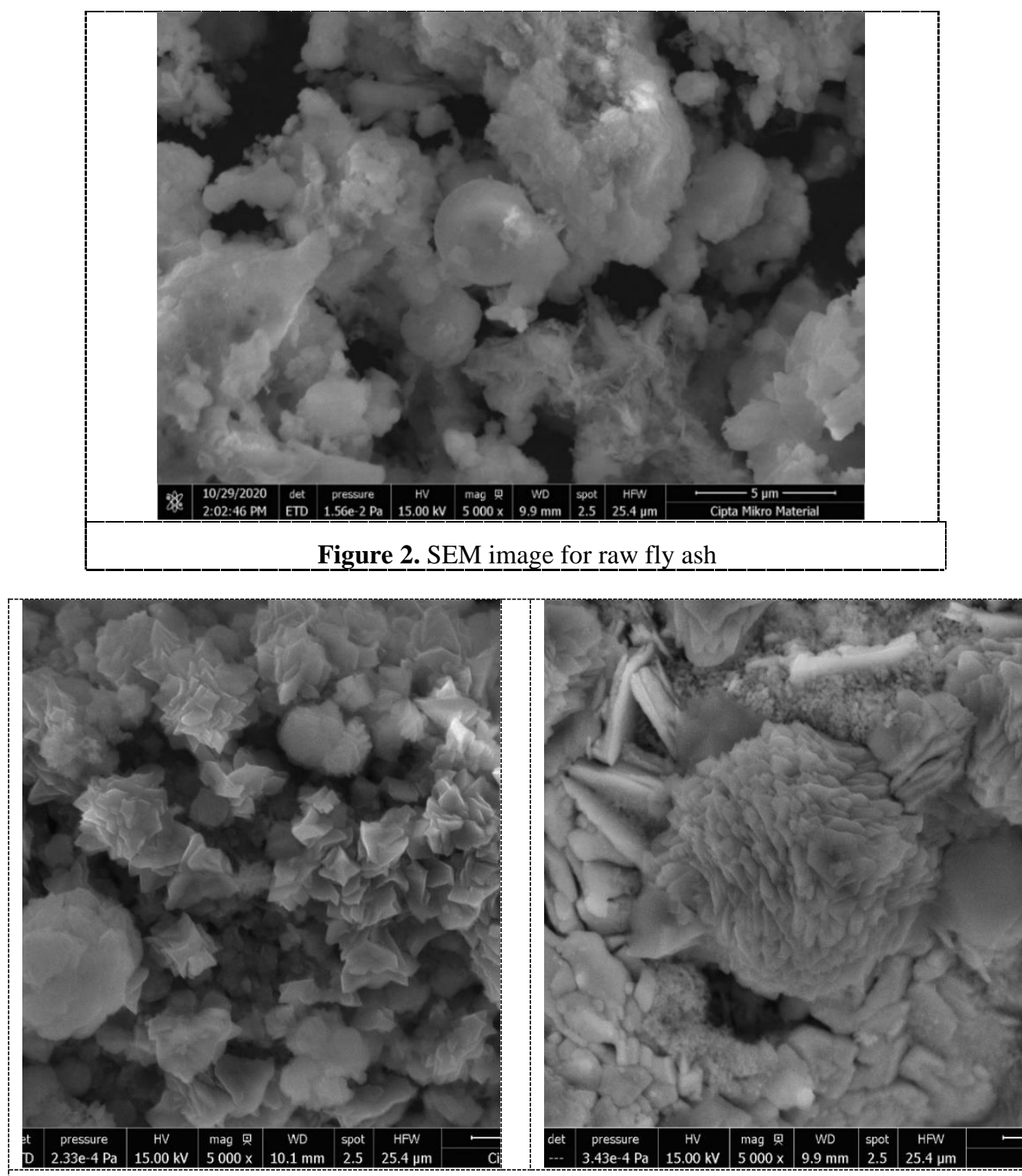

Figure 3. SEM image of zeolite with furnace pretreatment (left) and acidic pretreatment (right). 


\section{Conclusion}

Pretreatment of fly ash affects the properties of the zeolites produced. Furnace pretreatment did not have a significant impact on both fly ash and the resulting zeolite. Zeolite without pretreatment and zeolite with furnace pretreatment had similar properties and $\mathrm{Si} / \mathrm{Al}$ ratio although there was a slight difference in the morphology. Pretreatment using acid showed the best result on the resulting zeolite, proven by affecting the ratio $\mathrm{Si} / \mathrm{Al}$ of the resulting zeolite reaching 4.83. The SEM image of the finest zeolite shows a sharp crystal structure and high intensity peaks are seen in the XRD image. By lowering the trace, harmful, and unwanted materials from the fly ash that is the key to high intensity in XRD, acidic pretreatment causes a big weight reduction. For further research, it is suggested to test the effectiveness of the material for application in waste water treatment.

Acknowledgments. The Authors would like to thank the Directorate of Research and Community Engagement, Universitas Indonesia, for funding the research and publication cost through HIBAH PUTI with Grant No.: NKB-4926/UN2.RST/HKP.05.00/2020.

\section{Reference}

[1] R. H. Kupaei, U. J. Alengaram, and M. Z. Jumaat, "The Effect of Different Parameters on the Development of Compressive Strength of Oil Palm Shell Geopolymer Concrete," vol. 2014, 2014, doi: 10.1155/2014/898536.

[2] N. Toniolo and A. R. Boccaccini, "Fly ash-based geopolymers containing added silicate waste . A review," Ceram. Int., vol. 43, no. 17, pp. 14545-14551, 2017, doi: 10.1016/j.ceramint.2017.07.221.

[3] Y. Liu et al., "Synthesis of zeolite P1 from fly ash under solvent-free conditions for ammonium removal from water," J. Clean. Prod., 2018, doi: 10.1016/j.jclepro.2018.08.128.

[4] A. M. Cardoso, A. Paprocki, L. S. Ferret, C. M. N. Azevedo, and M. Pires, "Synthesis of zeolite Na-P1 under mild conditions using Brazilian coal fly ash and its application in wastewater treatment," FUEL, vol. 139, pp. 59-67, 2015, doi: 10.1016/j.fuel.2014.08.016.

[5] P. Joshi, "ScienceDirect Clean \& Sustainable process for Zeolite Synthesis : Effect of Acidic Pretreatment and Double Fusion on the Characteristics," Mater. Today Proc., vol. 4, no. 9, pp. 10484-10488, 2017, doi: 10.1016/j.matpr.2017.06.405.

[6] W. Franus and M. Wdowin, "Synthesis and characterization of zeolites prepared from industrial fly ash," 2014, doi: 10.1007/s10661-014-3815-5.

[7] D. R. Chaudhary and A. Ghosh, "Bioaccumulation of nutrient elements from fly ashamended soil in Jatropha curcas L : a biofuel crop,” pp. 6705-6712, 2013, doi: 10.1007/s10661-013-3058-x.

[8] A. Mehra, M. E. Farago, and D. K. Banerjee, "Impact of fly ash from coal-fired power stations in delhi, with particular reference to metal contamination," pp. 15-35, 1998.

[9] K. Nabih, "Synthesis of Zeolites Materials Using Fly Ash and Oil Shale Ash and Their Applications in Removing Heavy Metals from Aqueous Solutions," vol. 2018, 2018.

[10] C. F. Lin and H. C. Hsi, "Resource Recovery of Waste Fly Ash: Synthesis of Zeolitelike Materials," vol. 29, no. 4, pp. 9-17, 1995.

[11] K. Liu, M. Deng, and L. Mo, "Effect of Fly Ash on Resistance to Sulfate Attack of Cement-based Materials," vol. 539, pp. 124-129, 2013, doi: 10.4028/www.scientific.net/KEM.539.124. 
[12] P. Taylor, S. S. Banerjee, R. V Jayaram, and M. V Joshi, "Separation Science and Technology Removal of Nickel ( II ) and Zinc ( II ) from Wastewater Using Fly Ash and Impregnated Fly Ash," no. November 2014, pp. 37-41, 2006, doi: 10.1081/SS120018121.

[13] J. Chen, H. Kong, D. Wu, X. Chen, D. Zhang, and Z. Sun, "Phosphate immobilization from aqueous solution by fly ashes in relation to their composition," vol. 139, pp. 293300, 2007, doi: 10.1016/j.jhazmat.2006.06.034.

[14] B. Acemioglu, "Adsorption of Congo red from aqueous solution onto calcium-rich fly ash," vol. 274, pp. 371-379, 2004, doi: 10.1016/j.jcis.2004.03.019.

[15] M. Visa, "Synthesis and characterization of new zeolite materials obtained from fly ash for heavy metals removal in advanced wastewater treatment," Powder Technol., 2016, doi: 10.1016/j.powtec.2016.02.019.

[16] A. C618-05, "Standard Specification for Coal Fly Ash and Raw or Calcined Natural Pozzolan for Use," pp. 2005-2007, 2007.

[17] X. Ren et al., "Synthesis of Zeolites from Coal Fly Ash for the Removal of Harmful Gaseous Pollutants: A Review," pp. 1127-1144, 2020, doi: 10.4209/aaqr.2019.12.0651.

[18] X. Querol and A. Lbpez-soler, "Synthesis of Na-zeolites from fly ash," vol. 76, no. 8, pp. 793-799, 1997. 